\title{
Constructing isoluminant stimuli for word recognition research: A precautionary study
}

\author{
TIMOTHY R. JORDAN \\ University of Leicester, Leicester, England \\ SUSAN M. SHERMAN \\ Keele University, Staffordshire, England \\ AND \\ RICHARD P. TONKIN \\ University of Leicester, Leicester, England
}

\begin{abstract}
Isoluminant stimuli are used increasingly often to investigate processes underlying visual word recognition. However, construction of isoluminant stimuli is not straightforward, and inappropriate construction may have the result of misinforming theories that relate word recognition to neurological function. To inform the use of isoluminant stimuli in studies of word recognition, the present article details two experiments in which isoluminant stimuli were constructed using physical onscreen luminance matching and heterochromatic flicker photometry (HFP) with four different stimulus types: disks, squares, rectangles, and letter strings. The findings reveal (1) substantial differences between isoluminance determined by physical onscreen luminance matching and HFP, (2) substantial differences in HFP isoluminance across stimulus types, and (3) substantial differences in HFP isoluminance across participants. These findings indicate that, in contrast to common practice in word recognition research, HFP provides a better indication of isoluminance than physical onscreen matching; but HFP stimuli should match those used in the experiment proper and should be used to assess isoluminance individually for each participant.
\end{abstract}

A technique used widely in visual research is the presentation of stimuli containing no perceptible luminance differences and differing only in chromaticity. For example, presenting a red square on a green background, where the square and the background have perceptually the same luminance, creates a stimulus in which the square can be discriminated from the background through the use of processes that are sensitive to chromatic differences but not to differences in luminance. Stimuli such as these are referred to as being isoluminant (the term we use here) or equiluminant.

During the past decade or so, an increasing number of studies have used isoluminant stimuli to investigate processes underlying word recognition. One attraction of this approach is that, in the primate visual system, approximately $85 \%$ of cortical projections are organized along two parallel pathways - magnocellular (M) and parvocellular (P) - (see, e.g., Dacey, 2000; Lee, 1996; Livingstone \& Hubel, 1987). Although the two pathways may not be functionally wholly independent subsystems (see, e.g., Merigan \& Maunsell, 1993), numerous studies indicate that these two pathways are sensitive to different visual characteristics (for reviews, see Lee, 1996; Shapley, 1990). In particular, approximately $90 \%$ of $P$ cells receive input from specific pairs of cone types, the re- maining $10 \%$ receiving inputs from all cone types; all $\mathrm{M}$ cells receive input from all cone types. Thus, though the $\mathrm{P}$ pathway can discriminate colors readily, the M pathway cannot. This difference in the ability of the pathways to process color means that it is possible to use isoluminant displays to selectively impair processes that are reliant on M pathway functioning (see, e.g., Hicks, Lee, \& Vidyasagar, 1983; Lee, Martin, \& Valberg, 1988; Reid \& Shapley, 1992; Shapley, Reid, \& Kaplan, 1991; although see Logothetis, Schiller, Charles, \& Hurlbert, 1990), including those processes that contribute to word recognition. As a result, experiments using isoluminant stimuli may offer important clues about the neurological processing that subserves normal word recognition and is impaired when normal word recognition breaks down (for a recent review of this approach, see Allen, Smith, Groth, Pickle, Grabbe, \& Madden, 2002). ${ }^{1}$

The approach of using isoluminant stimuli has considerable promise and provides stimulating evidence about the nature of word recognition. For example, Legge, Parish, Luebker, and Wurm (1990) examined the effect of color and luminance contrast on reading rates and found that isoluminant text supported reading rates as fast as those obtained with nonisoluminant text. This suggests that word recognition is not impaired when M pathway activity is

T. R. Jordan, prof.timjordan@leicester.ac.uk 
suppressed by isoluminance and, therefore, that the sensory information required for word recognition is carried by the $\mathrm{P}$ pathway. This view is supported by the findings of Travis, Bowles, Seton, and Peppe (1990), who found "near perfect" single word recognition with isoluminant stimuli; that is, performance was no worse than with nonisoluminant word displays. However, the findings of Knoblauch, Arditi, and Szlyk (1991) indicate that reading rates are lower with isoluminant text than with nonisoluminant text. This provides some evidence of M pathway involvement in word recognition. The findings of Chase, Ashourzadeh, Kelly, Monfette, and Kinsey (2003), who used single word stimuli, also suggest that the $M$ pathway provides the dominant source of information for word recognition under normal contrast conditions (see also Allen et al., 2002; Floyd \& Dain, 2000; Kempner, Aggarwala, Zemon, Gordon, Hainline, \& Riddell, 1996; Lehky, 2000; Ojanpää \& Näsänen, 2003; Omtzigt, Hendriks, \& Kolk, 2002).

However, the generation of isoluminant stimuli for studying word recognition is not a simple matter. The most straightforward approach is to match the onscreen luminance of the different components so they have the same physical luminance, as measured by a photometer (see, e.g., Chase et al., 2003; Knoblauch et al., 1991; Lehky, 2000; Ojanpää \& Näsänen, 2003; Travis et al., 1990; see also Allen et al., 2002). Unfortunately, onscreen isoluminance does not guarantee that stimuli are isoluminant in either retinal images or postretinal neural responses (see, e.g., Bilodeau \& Faubert, 1997; see also Cavanagh, MacLeod, \& Anstis, 1987; Dobkins, Gunther, \& Peterzell, 2000; Livingstone \& Hubel, 1987; Metha \& Mullen, 1996; von Berg, Ziebell, \& Stiehl, 2002), and luminance differences may therefore be readily perceived by the observer. Consequently, an alternative approach to suppressing the processing of luminance contrasts in word recognition experiments is required.

One technique to be considered is dynamic random luminance masking (see, e.g., Barbur, Harlow, \& Plant, 1994; Birch, Barbur, \& Harlow, 1992), in which the use of luminance contrast to process a target stimulus is suppressed by rapid, random (within spatial and luminance limits) fluctuations in the luminance of the onscreen components in which the target is embedded. However, the effects of masking on word recognition are far from understood, and masking often results in unintended, misleading effects on word recognition (for discussions, see, e.g., Jordan, 1995; Jordan \& Bevan, 1994; Jordan \& de Bruijn, 1993). Moreover, the role of spatial attention in word recognition is well established (see, e.g., Johnston, 1981; Johnston \& McClelland, 1974; McCann, Folk, \& Johnston, 1992; Stolz \& McCann, 2000), and rapid local luminance fluctuations disrupt the allocation of normal attentional resources (see, e.g., Atchley, Kramer, \& Hillstrom, 2000; Franconeri, Hollingworth, \& Simons, 2005; Jonides \& Yantis, 1988; Yantis \& Jonides, 1984). Consequently, dynamic random luminance masking can be a particularly problematic procedure for use in investigating word recognition.

However, these problems can be avoided by using heterochromatic flicker photometry (HFP), which is conducted before the experiment proper, provides an apparently ef- fective technique for constructing stable, isoluminant experimental stimuli, and is, according to the literature, the most widely used technique for this purpose. When using HFP, a display component of one color is flickered with a display component of a different color, and participants are required to adjust the luminance of one of these components until the amount of visible flicker in the overall display is minimal. Regan and Lee (1993) compared the results of the HFP task with visual evoked potentials (VEPs) recorded from electrodes attached to human occipital scalp and with single cell responses from the retinal ganglion cells of macaques and found similar spectral-sensitivity curves for all three measures. This finding is supported by Di Russo, Spinelle, and Morrone (2001), who obtained isoluminance using HFP and then recorded VEPs from the midline and right side for each participant for stimulus presentations at the isoluminance setting determined by HFP, as well as at other nearby points. Di Russo et al. found that the HFP isoluminance setting equaled the lowest amplitude VEPs for all participants. The indications are, therefore, that HFP offers an effective assessment of what people perceive as being isoluminant.

However, the HFP task requires careful implementation if it is to be used effectively for studies of word recognition. In particular, evidence from psychophysical research using gratings suggests that the luminance values required for isoluminance in the HFP task may be affected by the physical properties of the stimuli used (see, e.g., Cavanagh et al., 1987; Dobkins et al., 2000; Metha \& Mullen, 1996). As a consequence, if the stimuli used in the HFP task to determine isoluminance differ substantially from the (word) stimuli being used in the experiment proper, the experiment proper may not constitute a valid investigation of the effects of isoluminance on word recognition.

To date, most studies using isoluminant stimuli to investigate word recognition have been based on isoluminance that was determined by equating physical onscreen luminance (Chase et al., 2003; Knoblauch et al., 1991; Ojanpää \& Näsänen, 2003; Travis et al., 1990; see also Allen et al., 2002; Lehky, 2000), so these studies are exposed to concerns about the validity of this approach. Some studies have used HFP (Floyd \& Dain, 2000; Legge et al., 1990; Omtzigt et al., 2002), but each of these studies used stimuli in the HFP task that differed substantially from the stimuli used to assess word recognition. Specifically, Floyd and Dain (2000) used rectangles, Legge et al. (1990) used squares, and Omtzigt et al. (2002) used disks. ${ }^{2}$ The precise effects of these mismatches on the assessment of word recognition performance in each of these studies is currently unknown, but the evidence available from psychophysical research suggests that the levels of isoluminance determined by the HFP tasks used in these studies was not appropriate for studying word recognition.

Accordingly, the purpose of the present study was to inform the construction of isoluminant stimuli for future studies of word recognition by comparing the definitions of isoluminant stimuli obtained with physical onscreen matching and with HFP using four different types of stimuli: disks, squares, rectangles, and letter strings. Disks, squares, and rectangles were selected to be representative of stimuli 
used previously in studies using HFP to investigate word recognition and were reasonable candidates for determining isoluminance for word recognition experiments. Letter strings were chosen to be representative of the stimuli used in word recognition experiments and are potentially, therefore, the most appropriate stimuli for use on the HFP task.

If the stimulus luminance required for isoluminance in the HFP task is dependent on stimulus type, differences in the luminance values required for isoluminance should be observed across the four stimuli in our experiment. Moreover, differences between the isoluminance values obtained using letter strings and those obtained using other stimuli would provide a crucial indication of the relative merits of using different HFP stimuli for studying effects of isoluminance in word recognition tasks. The use of all four stimuli would also provide a comprehensive comparison between the isoluminance values defined by physical onscreen matching and those defined by HFP.

\section{EXPERIMENT 1}

\section{Method}

Participants. Sixteen participants took part in two 1-hr sessions, for which they were paid. All participants were aged between 16 and 35 and reported having normal or corrected-to-normal vision. All participants were screened using a Bailey-Lovie eye chart (Bailey \& Lovie, 1976) for a normal minimum binocular acuity of 10/10 (3/3) and were tested for color blindness (Ishihara, 1977; Fletcher, 1980). Only those with normal color vision were allowed to participate.

Stimuli. At the viewing distance of $67 \mathrm{~cm}$, disks subtended a viewing angle of approximately $1.2^{\circ}$ in diameter, squares subtended a viewing angle of approximately $1.2^{\circ}$ horizontally and vertically, and rectangles and four-letter strings subtended viewing angles of approximately $1.2^{\circ}$ horizontally and $0.2^{\circ}$ vertically. (Viewing angles of $1.2^{\circ}$ horizontally and $0.2^{\circ}$ vertically are normal for reading four-letter words; see, e.g., Jordan, Thomas, Patching, \& Scott-Brown, 2003.) The letter string stimulus was composed of $x \mathrm{~s}$ ("xxxx") presented in lowercase 12-pt Times New Roman. This single string was used to equate the use of a single stimulus across the four stimulus conditions used in the experiment and to suppress any verbal interference in performing the task. All stimuli were presented in red or green against a background of the opposing color (green and red, respectively), which filled the display screen. These colors are commonly used to study effects of chromaticity on word recognition (see, e.g., Allen et al., 2002; Chase et al., 2003; Floyd \& Dain, 2000; Kempner et al., 1996; Legge et al., 1990; Ojanpää \& Näsänen, 2003; Omtzigt et al., 2002; Travis et al., 1990). Two flicker rates were used: $16 \mathrm{~Hz}$ and $20 \mathrm{~Hz}$. These rates were chosen for their suitability for magnocellular processing (see, e.g., Dobkins et al., 2000) and on the basis of a pilot study in which participants found performing the HFP task to be straightforward when these rates were used. The chromatic and luminance characteristics of the display screen were measured using a Cambridge Research Systems ColorCAL colorimeter. The maximum luminances available for red, green, and blue were 20.6, 55.7, and $5.7 \mathrm{~cd} / \mathrm{m}^{2}$, respectively. The CIE $(x, y)$ coordinates of the display screen were $(.61, .34)$ for the red phosphor, $(.28, .60)$ for the green phosphor, and $(.15, .07)$ for the blue phosphor. The luminance of the red and green backgrounds was $13.5 \mathrm{~cd} / \mathrm{m}^{2}$, and the CIE coordinates were $(.61, .34)$ and $(.28, .60)$, respectively. Gamma correction was run to ensure that each luminance adjustment affected the luminance of each stimulus by the same amount.

Design. All three variables were manipulated in a within-subjects design: 4 (stimulus type: disk, square, rectangle, letter string) $\times 2$ (flicker rate: $16 \mathrm{~Hz}, 20 \mathrm{~Hz}) \times 2$ (color: green stimuli/red background, red stimuli/green background). The starting luminance for the stimu- lus color was randomly assigned for each trial. The order in which the 16 conditions were shown was randomized for each participant. For each condition, each participant received a block of 20 trials.

Apparatus. The experiment was controlled by a Cambridge Research Systems visual stimulus generator (VSG 2/5) card. Stimuli were presented on a high-resolution color monitor. Participants adjusted the luminance of the stimulus color, and their responses were recorded, using a Cambridge Research Systems CT3 response box. The screen was visible through a matte black cowl attached to the monitor, which maintained viewing distance and prevented reflections. The experiment was conducted in a darkened room.

Procedure. The experiment was split into two sessions. Each participant performed a set of practice trials at the start of each session. For each trial, participants were presented a flickering stimulus (disk, square, rectangle, or letter string) and could increase and decrease the luminance of the stimulus by pressing the up and down keys, respectively, on the response box. Participants were instructed to adjust stimulus luminance so that visible flicker was minimal. When they were satisfied that this had been achieved, they pressed a third button on the response box, and the luminance value was recorded. No feedback on performance was given to the participants during the experiment.

\section{Results}

The mean stimulus luminance values required to achieve minimal flicker are shown in Figure 1. Responses were analyzed using a repeated measures ANOVA with three within-subjects variables: 2 (flicker rate: $16 \mathrm{~Hz}$, $20 \mathrm{~Hz}) \times 4$ (stimulus type: disk, square, rectangle, letter string) $\times 2$ (color: green stimulus/red background, red stimulus/green background).

There were significant main effects of stimulus type $[F(3,45)=84.73, p<.0001]$ and color $[F(1,15)=46.87$, $p<.0001]$ and a significant interaction between the two $[F(3,45)=25.69, p<.0001]$. However, neither the main effect of flicker rate nor any other interactions were significant (all $p \mathrm{~s}>.12$ ). Newman-Keuls tests revealed that the luminance of green stimuli required to achieve isoluminance was lowest for disks, higher for rectangles, higher still for squares, and highest of all for letter strings (all $p \mathrm{~s}<.01$ ). The luminance of red stimuli required to achieve isoluminance did not differ across disks, squares, and rectangles (all $p \mathrm{~s}>.10$ ), but was higher for letter strings than for all other stimulus types (all $p \mathrm{~s}<.01$ ). For all stimulus types, green stimuli required a higher luminance than red stimuli to achieve isoluminance (all $p \mathrm{~s}<.01$ ), but this difference between required red and green luminance levels varied across stimulus types: It was smallest for disks, larger for rectangles, larger still for squares, and largest of all for letter strings (all $p \mathrm{~s}<.01$ ).

Comparisons using $t$ tests with Bonferroni correction (Bonferroni adjusted alpha of .00625) showed that the stimulus luminance required to achieve isoluminance for green stimuli was higher than background luminance for each stimulus type; but this increment was smallest for disks, larger for rectangles, larger still for squares, and largest of all for letter strings. Similar comparisons showed that the stimulus luminance required to achieve isoluminance for red stimuli was lower than background luminance for disks, squares, and rectangles, but higher than background luminance for letter strings.

A by-participants ANOVA showed a significant main effect of participant $[F(15,225)=2.69, p<.001]$. Newman- 

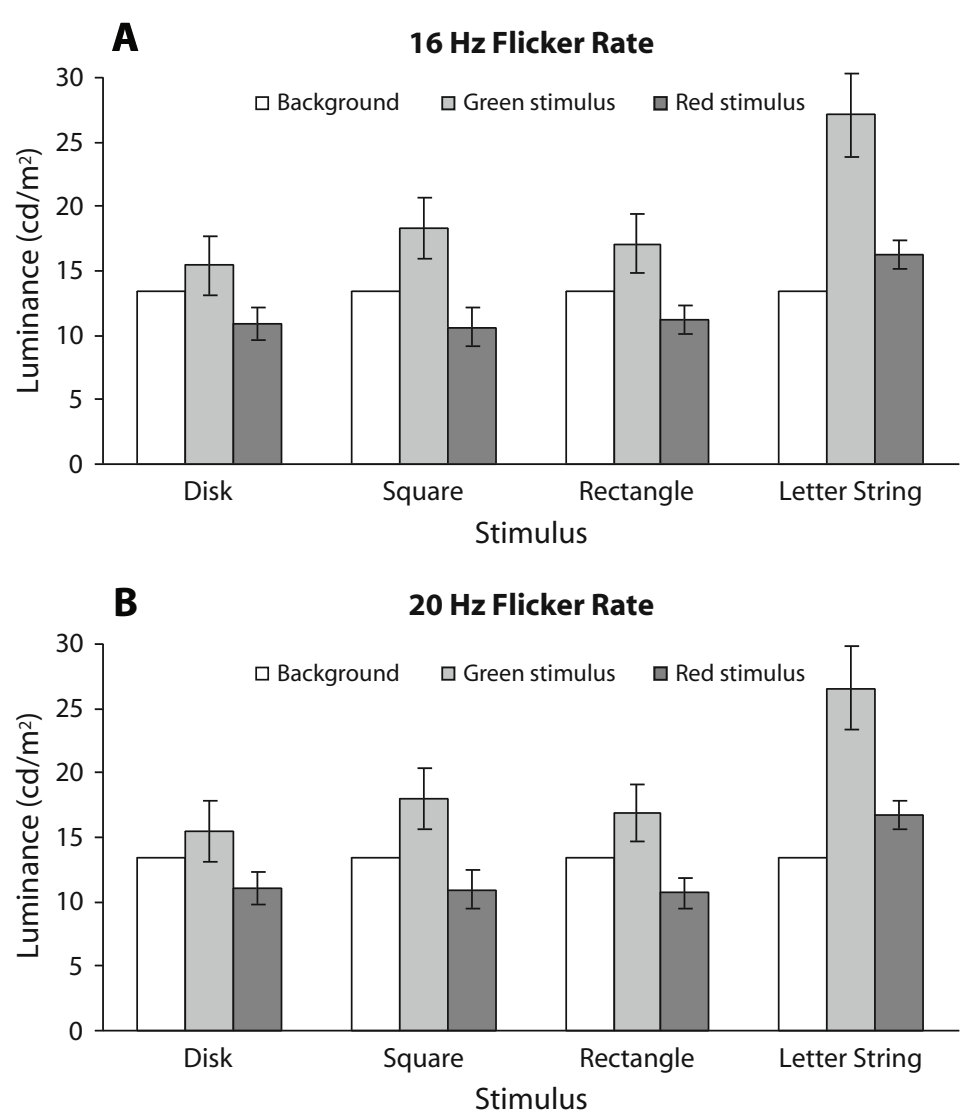

Figure 1. Mean stimulus luminances required to achieve minimal flicker in the HFP task for the different stimulus conditions at flicker rates of $(A) 16 \mathrm{~Hz}$ and (B) $20 \mathrm{~Hz}$. Background luminance indicates the physical onscreen luminance of the background of each display and, therefore, the stimulus luminance required for a physical luminance match. Bars denote the mean standard deviation for each condition.

Keuls tests showed that the mean luminance required to achieve isoluminance was higher for Participants 3, 5, 6, 9, and 15 than for Participants 1, 2, 4, 7, 8, 10, 11, 13, and 16; was higher for Participants 12 and 14 than for Participants 1, 2, 7, and 10; and was higher for Participants 4, 8, 11,13 , and 16 than for Participant 7 (all $p \mathrm{~s}<.01$ ).

The standard deviations of the 20 responses in each condition were also analyzed using a repeated measures ANOVA with the same three within-subjects variables as before. This was carried out to reveal the consistency with which participants responded over trials within each condition. The analysis showed main effects of stimulus type $[F(3,45)=12.14, p<.0001]$ and color $[F(1,15)=$ $14.92, p<.005]$, as well as an interaction between these two variables $[F(3,45)=3.27, p<.05]$. NewmanKeuls tests revealed that when green stimuli were manipulated, the mean standard deviation for letter strings $\left(M=3.22 \mathrm{~cd} / \mathrm{m}^{2}\right)$ was larger than that for disks $(M=$ $\left.2.35 \mathrm{~cd} / \mathrm{m}^{2}, p<.05\right)$, squares $\left(M=2.41 \mathrm{~cd} / \mathrm{m}^{2}, p<.05\right)$, and rectangles $\left(M=2.28 \mathrm{~cd} / \mathrm{m}^{2}, p<.01\right)$. No differences among disks, squares, and rectangles were significant (all $p$ s $>.10)$. For red stimuli, no significant differences were found among letter strings $\left(M=1.12 \mathrm{~cd} / \mathrm{m}^{2}\right)$, disks $(M=$ $\left.1.29 \mathrm{~cd} / \mathrm{m}^{2}\right)$, squares $\left(M=1.50 \mathrm{~cd} / \mathrm{m}^{2}\right)$, or rectangles $\left(M=1.17 \mathrm{~cd} / \mathrm{m}^{2}\right.$, all $\left.p s>.10\right)$. Mean standard deviations for all stimulus types were significantly larger for green stimuli than for red stimuli (all $p$ s $<.05$ ). For each condition, standard deviations showed no sign of asymmetry above or below the mean (all $p \mathrm{~s}>.30$ ).

\section{Discussion}

These findings highlight the importance of using letter strings in HFP tasks when generating isoluminant stimuli for studies that examine word recognition processes. Indeed, the discrepancies in luminance among letter strings and other stimulus types were substantial for red and green stimuli, although greatest for green stimuli. It is also clear that, despite a red-green color contrast throughout Experiment 1 , the stimulus luminances required to achieve isoluminance were higher for green stimuli/red backgrounds than for red stimuli/green backgrounds, suggesting that sensitivity to stimulus luminance was generally lower for green stimuli/red backgrounds. Previous investigations of the influence of color on visual processing indicate that red backgrounds have a special ability to selectively suppress activity in the M pathway and to impair stimulus process- 
ing (see, e.g., Breitmeyer \& Breier, 1994; Breitmeyer \& Williams, 1990; Chase et al., 2003; Hellige \& Cumberland, 2001; Maehara, Okubo, \& Michimata, 2004). Consequently, it seems likely that a similar effect was present in Experiment 1, providing further evidence of the relevance of the HFP task for investigations of M pathway processing.

The widespread differences between the isoluminance values defined by physical onscreen matching and by HFP highlight the inadequacy of using physical onscreen matching to produce isoluminant stimuli. Indeed, this inadequacy is underscored by the importance of using different luminance levels to provide perceptual isoluminance across different types of stimuli and across different participants, which physical onscreen matching would fail to accommodate.

The broadly similar levels of performance observed for disks, squares, and rectangles in the HFP task reflect the shared spatial frequency composition of these stimuli (see, e.g., Dobkins et al., 2000). In a similar vein, the very different levels of performance observed for letter strings in comparison with those for other stimulus types reflect the higher spatial frequency components of letter string stimuli and the absence of these components from the other stimulus types. Thus, although the spatial frequencies used for recognizing words are probably well within the sensitivity range of the $\mathrm{M}$ pathway (see, e.g., Chase et al., 2003; Legge, Pelli, Rubin, \& Schleske, 1985; Lynch, Silveira, Perry, \& Merigan, 1992; Majaj, Pelli, Kurshan, \& Palomares, 2002), the presence and combination of these frequencies in letter strings are likely to make letter strings something of a special visual case (see also Patching \& Jordan, 2005a, 2005b).

Green stimuli/red backgrounds also produced generally higher levels of variance than did red stimuli/green backgrounds, particularly for letter strings. This underscores the suggestion that luminance sensitivity on the HFP task in Experiment 1 was generally lower for green stimuli/ red backgrounds and may have been particularly low for green letter strings. We sought to remove this discrepancy in Experiment 2.

Mäkelä, Rovamo, and Whitaker (1994) found that sensitivity to luminance flicker may be lower with smaller stimuli. This finding suggests that sensitivity on the HFP task may be increased by increasing the size of the adjusted stimulus. In Experiment 1, the size of each type of stimulus (disk, square, rectangle, letter string) was small relative to the background. Moreover, although squares, disks, and rectangles were selected to reflect stimuli used previously in studies using HFP - and rectangles and letter strings were matched for their overall extent - the surface areas of the stimuli were related in the following manners: larger for squares than for disks, larger for disks than for rectangles, and smallest of all for letter strings. This may have contributed to the increased variation in performance observed with green letter strings. The similar patterns of variance observed across all red stimuli and across green disks, green squares, and green rectangles, indicate that stimulus size alone did not determine the variance ob- served in Experiment 1. Nevertheless, to increase the sensitivity of the HFP task, especially for displays using green stimuli/red backgrounds, we used the same displays in Experiment 2 as in Experiment 1; but now the luminance of each stimulus was fixed, and participants were required to adjust the luminance of each background in order to minimize visible flicker. This change in procedure from Experiment 1 had the advantage of maintaining the use of natural-sized letter strings while substantially increasing the size of the adjusted stimulus.

\section{EXPERIMENT 2}

\section{Method}

Participants. Sixteen participants from the same population as in Experiment 1 took part in two 1-hr sessions, for which they were paid.

Stimuli and Procedure. The luminance of red and green stimuli (disk, square, rectangle, and letter string) was $13.5 \mathrm{~cd} / \mathrm{m}^{2}$, and the CIE coordinates were $(.61, .34)$ and $(.28, .60)$, respectively. The starting luminance for each background was randomly assigned for each trial. For each trial, participants were presented a flickering background. By pressing the up and down keys on the response box, participants could increase and decrease (respectively) the luminance of the background. Participants were instructed to adjust this luminance in order to minimize visible flicker. All other aspects of Experiment 2 were identical to those of Experiment 1.

\section{Results}

The mean background luminance values required to achieve minimal flicker are shown in Figure 2. Responses were analyzed as in Experiment 1.

There were significant main effects of stimulus type $[F(3,45)=62.33, p<.0001]$ and color $[F(1,15)=26.59$, $p<.0001]$ and a significant interaction between the two $[F(3,45)=15.49, p<.0001]$. Neither the main effect of flicker rate nor any other interactions were significant (all $p \mathrm{~s}>.15)$. Newman-Keuls tests revealed that the luminance of red backgrounds required to achieve isoluminance was highest for disks, lower for rectangles, lower still for squares, and lowest of all for letter strings (all $p s<.01)$. The luminance of green backgrounds that was required to achieve isoluminance did not differ across disks, squares, and rectangles (all $p$ s $>.10$ ), but was lower for letter strings (all $p \mathrm{~s}<.01$ ). For each stimulus type, red backgrounds required a lower luminance than did green backgrounds to achieve isoluminance (all $p \mathrm{~s}<.01$ ), but this difference varied across stimulus type: It was smallest for disks, larger for rectangles, larger still for squares, and largest of all for letter strings (all $p \mathrm{~s}<.01$ ).

Comparisons using $t$ tests with Bonferroni correction (Bonferroni adjusted alpha of .00625) showed that the luminance of red backgrounds required to achieve isoluminance was lower than stimulus luminance for each stimulus type, but this decrement was smallest for disks, larger for rectangles, larger still for squares, and largest of all for letter strings. Similar comparisons showed that the luminance of green backgrounds required to achieve isoluminance was higher than stimulus luminance for disks, squares, and rectangles, but was lower than stimulus luminance for letter strings. 

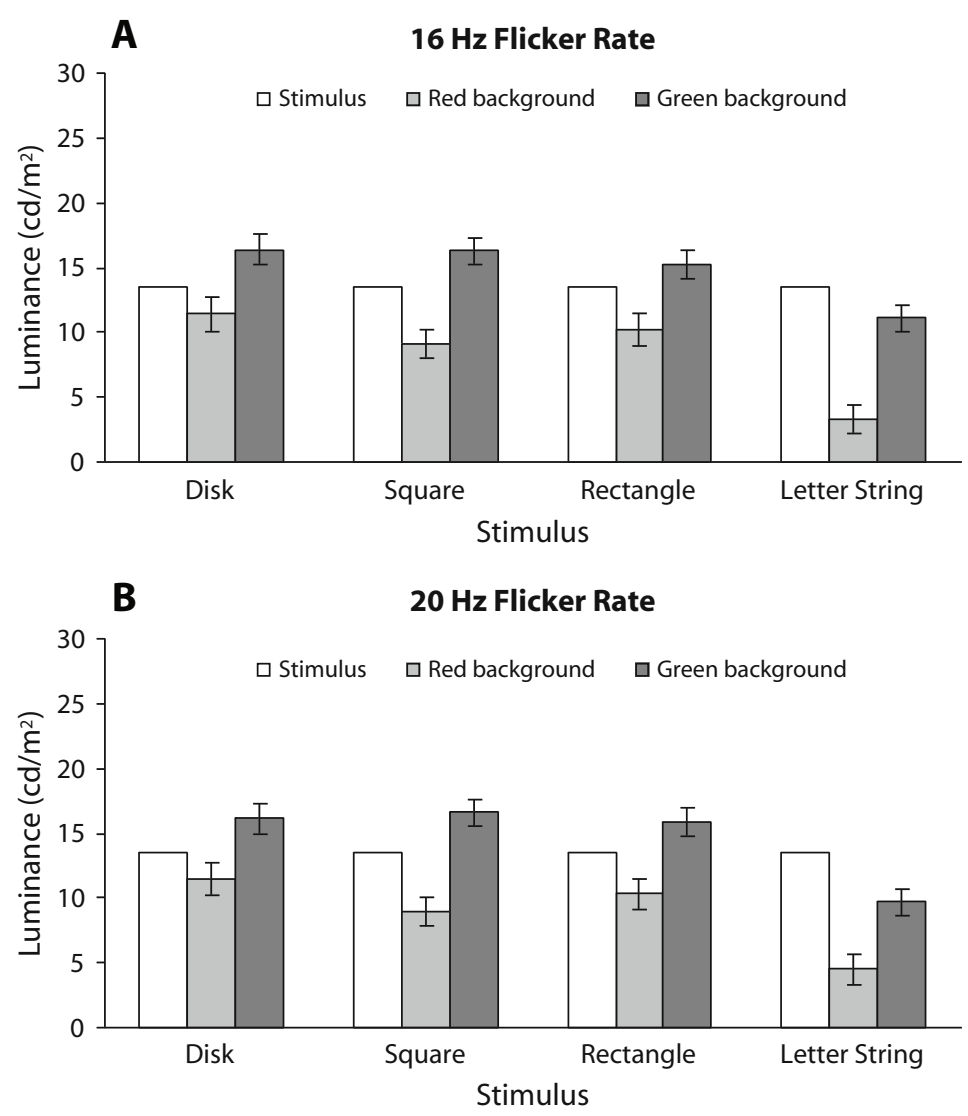

Figure 2. Mean background luminances required to achieve minimal flicker in the HFP task for the different stimulus conditions at flicker rates of (A) $16 \mathrm{~Hz}$ and (B) $20 \mathrm{~Hz}$. Stimulus luminance indicates the physical onscreen luminance of the stimulus of each display and, therefore, the background luminance required for a physical luminance match. Bars denote the mean standard deviation for each condition.

A by-participants ANOVA showed a significant main effect of participant $[F(15,225)=3.44, p<.001]$. Newman-Keuls tests showed that the mean luminance required to achieve isoluminance was higher for Participants 3, 7, 10, and 13 than for Participants 1, 4, 5, 6, 8, 11, 12, 14, and 15; was higher for Participants 2, 9, and 16 than for Participants 5, 11, and 14; and was higher for Participants 1, 4, 6, 8, 12, and 15 than for Participant 11 (all $p$ s $<.01)$.

The standard deviations of the 20 responses in each condition were analyzed as in Experiment 1. The analysis showed no main effects or interactions. For green stimuli, mean standard deviations were $1.14 \mathrm{~cd} / \mathrm{m}^{2}$ for letter strings, $1.27 \mathrm{~cd} / \mathrm{m}^{2}$ for disks, $1.08 \mathrm{~cd} / \mathrm{m}^{2}$ for squares, and $1.22 \mathrm{~cd} / \mathrm{m}^{2}$ for rectangles. For red stimuli, mean standard deviations were $1.03 \mathrm{~cd} / \mathrm{m}^{2}$ for letter strings, $1.21 \mathrm{~cd} / \mathrm{m}^{2}$ for disks, $1.02 \mathrm{~cd} / \mathrm{m}^{2}$ for squares, and $1.10 \mathrm{~cd} / \mathrm{m}^{2}$ for rectangles. For each condition, standard deviations showed no sign of asymmetry above or below the mean (all $p \mathrm{~s}>.10$ ).

\section{Discussion}

Despite the shift in procedure (adjusting background luminance), Experiment 2 produced essentially the same patterns of isoluminance as did Experiment 1, providing a useful replication of those findings. However - as we had hoped - the shift in procedure removed the differences in variance observed in Experiment 1.

\section{GENERAL DISCUSSION}

The first point to emerge from the findings of this study is that, although HFP can provide an effective assessment of isoluminance for studying word recognition, the luminance required for perceived isoluminance varies considerably with the type of stimulus used. Indeed, it is of particular concern that, although all stimuli produced different luminance requirements, the luminance requirements of letter strings differed substantially from those of all other stimuli. These findings generally caution that the assessment of isoluminance using HFP is likely to provide appropriate isoluminant displays in an experiment only if the same type of stimulus is used in both the HFP task and the experiment proper; this caution should be of particular concern to researchers who wish to investigate effects of isoluminance on word recognition. The clear indication is that word recognition studies in which stimuli used in 
the HFP task are not of the same type as those used in the experiment proper will not constitute valid investigations of effects of isoluminance on word recognition.

In addition to the problems associated with using inappropriate types of stimuli, previous studies using the HFP task have employed a variety of colors for stimuli and backgrounds, sometimes driven by theories about which colors are most appropriate for distinguishing the processing of $\mathrm{M}$ pathways from that of $\mathrm{P}$ pathways (see, e.g., Floyd \& Dain, 2000; Legge et al., 1990; Omtzigt et al., 2002). We find that the choice of color affects sensitivity to luminance on the HFP task considerably, which indicates the need for further considerations when interpreting the findings of studies in which the HFP task is used to produce isoluminant stimuli. In Experiment 1, as they adjusted the luminance of stimuli, participants showed more sensitivity to the luminance of red stimuli on green backgrounds than to the luminance of green stimuli on red backgrounds, and different levels of isoluminance were indicated by each color combination. However, from the results of Experiment 2, we found that manipulating the luminance of backgrounds rather than that of stimuli can provide a more sensitive way of determining isoluminance, although the findings of both experiments indicate the importance of using letters strings to determine isoluminance in studies of word recognition processes. Indeed, from the available evidence, we see that producing isoluminant displays in the HFP task by using stimuli on a red background and adjusting the luminance of the background - and then presenting the resultant displays in the experiment proper - offers a useful development of the HFP technique for suppressing M pathway activity. ${ }^{3}$

Finally, the findings of this study underscore the concern (see, e.g., Bilodeau \& Faubert, 1997; Dobkins et al., 2000) that, despite the popularity of the approach (see, e.g., Chase et al., 2003; Knoblauch et al., 1991; Ojanpää \& Näsänen, 2003; Travis et al., 1990; see also Allen et al., 2002; Lehky, 2000), matching the physical onscreen luminance of stimuli and backgrounds is not an effective technique for determining isoluminance. According to the findings obtained using HFP in our study, it is likely that no stimulus type, including letter strings, would be perceived as isoluminant when presented at the same physical luminance as the background; stimulus luminances would not provide a perceptual match, thus allowing observers to perceive luminance differences between stimuli and the background. Indeed, the greatest discrepancies were observed when green letter strings were presented on a red background (see also Chase et al., 2003), where the stimulus luminance required to produce isoluminant displays in the HFP task was more than twice the luminance of the background. Moreover, while HFP can accommodate individual differences in perceived isoluminance - and individual differences were apparent in our experiments - physical onscreen matching provides no such accommodation. Consequently, whereas matching physical onscreen luminance may appear to be an acceptable method of producing isoluminant displays, experiments using this technique are unlikely to constitute valid investigations of effects of isoluminance on word recognition processes.

\section{AUTHOR NOTE}

This work was supported by grants from the BBSRC (No. S12111) and the Wellcome Trust (No. 059727) to T. J. We are grateful to Patrick Cavanagh and Geoffrey Patching for comments on this work. Correspondence concerning this article should be addressed to T. R. Jordan, School of Psychology, Faculty of Medicine and Biological Sciences, Henry Wellcome Building, University of Leicester, Leicester LE1 9HN, England (e-mail: prof.timjordan@leicester.ac.uk).

\section{REFERENCES}

Allen, P. A., Smith, A. F., Groth, K. E., Pickle, J. L., Grabbe, J. W., \& Madden, D. J. (2002). Differential age effects for case and hue mixing in visual word recognition. Psychology \& Aging, 17, 622-635.

Atchley, P., Kramer, A. F., \& Hillstrom, A. P. (2000). Contingent capture for onsets and offsets: Attentional set for perceptual transients. Journal of Experimental Psychology: Human Perception \& Performance, 26, 594-606.

Bailey, I. L., \& Lovie, J. E. (1976). New design principles for visual acuity letter charts. American Journal of Optometry \& Physiological Optics, 53, 740-745.

Barbur, J. L., Harlow, A. J., \& Plant, G. T. (1994). Insights into the different exploits of color in the visual cortex. Proceedings of the Royal Society of London: Series B, 25, 327-334.

BilodeAu, L., \& FAUBerT, J. (1997). Isoluminance and chromatic motion perception throughout the visual field. Vision Research, 37, 20732081.

Birch, J., Barbur, J. L., \& Harlow, A. J. (1992). New method based on random luminance masking for measuring isochromatic zones using high resolution color displays. Ophthalmic \& Physiological Optics, 12, 133-136.

Breitmeyer, B. G., \& Breier, J. I. (1994). Effects of background color on reaction time to stimuli varying in size and contrast: Inferences about human M channels. Vision Research, 34, 1039-1045.

Breitmeyer, B. G., \& Williams, M. C. (1990). Effects of isoluminantbackground color on metacontrast and stroboscopic motion: Interactions between sustained (P) and transient (M) channels. Vision Research, 30, 1069-1075.

Cavanagh, P., MacLeod, D. I. A., \& Anstis, S. M. (1987). Equiluminance: Spatial and temporal factors and the contribution of bluesensitive cones. Journal of the Optical Society of America A, 4, $1428-1438$

Chase, C., Ashourzadeh, A., Kelly, C., Monfette, S., \& Kinsey, K. (2003). Can the magnocellular pathway read? Evidence from studies of color. Vision Research, 43, 1211-1222.

DACEY, D. M. (2000). Parallel pathways for spectral coding in primate retina. Annual Review of Neuroscience, 23, 743-775.

Di Russo, F., Spinelli, D., \& Morrone, M. C. (2001). Automatic gain control contrast mechanisms are modulated by attention in humans: Evidence from visual evoked potentials. Vision Research, 41, 2435-2447.

Dobkins, K. R., Gunther, K. L., \& Peterzell, D. H. (2000). What covariance mechanisms underlie green/red equiluminance, luminance contrast sensitivity, and chromatic (green/red) contrast sensitivity? Vision Research, 40, 613-628.

Fletcher, R. (1980). Second edition of the City University Test. In G. Verriest (Ed.), Colour vision deficiencies V (pp. 195-196). Bristol, U.K.: Adam Hilger.

FLOYD, R. A., \& DAIN, S. J. (2000). Heterochromatic flicker photometry and brightness matching in poor readers and normal controls. Investigative Ophthalmology \& Visual Science, 41, 2304.

Franconeri, S. L., Hollingworth, A., \& Simons, D. J. (2005). Do new objects capture attention? Psychological Science, 16, 275-281.

Hellige, J. B., \& Cumberland, N. (2001). Categorical and coordinate spatial processing: More on contributions of the transient/ magnocellular visual system. Brain \& Cognition, 45, 155-163.

Heywood, C. A., Cowey, A., \& Newcombe, F. (1994). On the role of parvocellular $(\mathrm{P})$ and magnocellular $(\mathrm{M})$ pathways in cerebral achromatopsia. Brain, 117, 245-254.

Hicks, T. P., Lee, B. B., \& Vidyasagar, T. R. (1983). The responses of cells in macaque lateral geniculate nucleus to sinusoidal gratings. Journal of Physiology, 337, 183-200. 
IsHIHARA, S. (1977). Tests for color-blindness: 24 plates. Tokyo: Kanehara Shuppan Co.

JOHNSTON, J. C. (1981). Effects of advanced precuing of alternatives on the perception of letters alone and in words. Journal of Experimental Psychology: Human Perception \& Performance, 7, 560-572.

Johnston, J. C., \& McClelland, J. L. (1974). Perception of letters in words: Seek not and ye shall find. Science, 184, 1192-1194.

Jonides, J., \& YANTIS, S. (1988). Uniqueness of abrupt visual onset in capturing attention. Perception \& Psychophysics, 43, 346-354.

JoRDAN, T. R. (1995). Perceiving exterior letters of words: Differential influences of letter-fragment and non-letter-fragment masks. Journal of Experimental Psychology: Human Perception \& Performance, 21, $512-530$

JoRDAN, T. R., \& BEVAN, K. M. (1994). Word superiority over isolated letters: The neglected case of forward masking. Memory \& Cognition, 22, 133-144.

JoRDAN, T. R., \& DE BRUIJN, O. (1993). Word superiority over isolated letters: The neglected role of flanking mask-contours. Journal of Experimental Psychology: Human Perception \& Performance, 19, 549-563.

Jordan, T. R., Thomas, S. M., Patching, G. R., \& Scott-Brown, K. C. (2003). Assessing the importance of letter pairs in initial, exterior, and interior positions in reading. Journal of Experimental Psychology: Learning, Memory, \& Cognition, 29, 883-893.

Kempner, F., Aggarwala, K. R., Zemon, V., Gordon, J., HainLINE, L., \& RIDDELL, P. M. (1996). Visually evoked potentials of adult specific reading disabled and control subjects to isoluminant visual stimuli. Investigative Ophthalmology \& Visual Science, 37 (Suppl.), 4948-B558.

Knoblauch, K., Arditi, A., \& Szlyk, J. (1991). Effects of chromatic and luminance contrast on reading. Journal of the Optical Society of America A, 8, 428-439.

LeE, B. B. (1996). Receptive field structure in the primate retina. Vision Research, 36, 631-644.

Lee, B. B., Martin, P. R., \& Valberg, A. (1988). The physiological basis of heterochromatic flicker photometry demonstrated in the ganglion cells of the macaque retina. Journal of Physiology, 404, 323-347.

Legge, G. E., Parish, D. H., LuebKer, A., \& Wurm, L. H. (1990). Psychophysics of reading: XI. Comparing color contrast and luminance contrast. Journal of the Optical Society of America A, 7, 2002-2010.

LegGe, G. E., Pelli, D. G., Rubin, G. S., \& Schleske, M. M. (1985). Psychophysics of reading: I. Normal vision. Vision Research, 25, 239-252.

LEHKY, S. R. (2000). Deficits in visual feature binding under isoluminant conditions. Journal of Cognitive Neuroscience, 12, 383-392.

Livingstone, M. S., \& Hubel, D. H. (1987). Psychophysical evidence for separate channels for the perception of form, color, movement, and depth. Journal of Neuroscience, 7, 3416-3468.

Logothetis, N. K., Schiller, P. H., Charles, E. R., \& Hurlbert, A. C. (1990). Perceptual deficits and the activity of the color-opponent and broad-band pathways at isoluminance. Science, 247, 214-217.

Lynch, J., Silveira, L., Perry, V., \& Merigan, W. (1992). Visual effects of damage to P ganglion cells of macaques. Visual Neuroscience, 8, 575-583.

Maehara, G., Okubo, M., \& Michimata, C. (2004). Effects of background color on detecting spot stimuli in the upper and lower visual fields. Brain \& Cognition, 55, 558-563.

Majaj, N. J., Pelli, D. G., Kurshan, P., \& Palomares, M. (2002). The role of spatial frequency channels in letter identification. Vision Research, 42, 1165-1184.

MäKelë, P., Rovamo, J., \& Whitaker, D. (1994). Effects of luminance and external temporal noise on flicker sensitivity as a function of stimulus size at various eccentricities. Vision Research, 34, 1981-1991.

McCann, R. S., Folk, C. L., \& Johnston, J. C. (1992). The role of spatial attention in visual word processing. Journal of Experimental Psychology: Human Perception \& Performance, 18, 1015-1029.

Merigan, W. H., \& Maunsell, J. H. R. (1993). How parallel are the primate visual pathways? Annual Review of Neuroscience, 16, 369-402.
Metha, A. B., \& Mullen, K. T. (1996). Temporal mechanisms underlying flicker detection and identification for red-green and achromatic stimuli. Journal of the Optical Society of America A, 13, 1969-1980.

OJANPÄ̈̈, H., \& NÄSÄNEN, R. (2003). Effects of luminance and color contrast on the search of information on display devices. Displays, 24, 167-178.

Omtzigt, D., Hendriks, A. W., \& KolK, H. H. J. (2002). Evidence for magnocellular involvement in the identification of flanked letters. Neuropsychologia, 40, 1881-1890.

Patching, G. R., \& JoRDAn, T. R. (2005a). Spatial frequency sensitivity differences between adults of good and poor reading ability. Investigative Ophthalmology \& Visual Science, 46, 2219-2224.

Patching, G. R., \& JoRdan, T. R. (2005b). Assessing the role of different spatial frequencies in word perception by good and poor readers. Memory \& Cognition, 33, 961-971.

Regan, D., \& LEE, B. B. (1993). A comparison of the 40-Hz response in man, and the properties of macaque ganglion-cells. Visual Neuroscience, 10, 439-445.

ReID, R. C., \& Shapley, R. M. (1992). Spatial structure of cone inputs to receptive fields in primate lateral geniculate nucleus. Nature, 356, 716-718.

ShaPLEy, R. (1990). Visual sensitivity and parallel retinocortical channels. Annual Review of Psychology, 41, 635-658.

Shapley, R., Reid, R. C., \& Kaplan, E. (1991). Receptive field structure of $\mathrm{M}$ and $\mathrm{P}$ cells in the monkey retina. In A. Valberg \& B. B. Lee (Eds.), From pigments to perception: Advances in understanding visual processes (pp. 95-104). New York: Plenum.

Stolz, J. A., \& McCanN, R. S. (2000). Visual word recognition: Reattending to the role of spatial attention. Journal of Experimental Psychology: Human Perception \& Performance, 26, 1320-1331.

Travis, D. S., Bowles, S., Seton, J., \& Peppe, R. (1990). Reading from color displays: A psychophysical model. Human Factors, 32, $147-156$.

von Berg, J., Ziebell, O., \& STIEhl, H. S. (2002). Texture segmentation performance related to cortical geometry. Vision Research, 42, 1917-1929.

YAntis, S., \& Jonides, J. (1984). Abrupt visual onsets and selective attention: Evidence from visual search. Journal of Experimental Psychology: Human Perception \& Performance, 10, 601-621.

\section{NOTES}

1. The anatomical, physiological, and psychophysical parameters of $\mathrm{M}$ and $\mathrm{P}$ functioning have yet to be fully resolved. Consequently, it would be inappropriate to argue that isoluminant stimuli silence $M$ pathway activity completely. However, there is widespread consensus based on current anatomical, physiological, and psychophysical knowledge that isoluminant stimuli suppress $\mathrm{M}$ pathway activity considerably and, therefore, that isoluminant stimuli can help elucidate the roles of $\mathrm{M}$ and $P$ pathway functioning.

2. Travis, Bowles, Seton, and Peppe (1990) used physical onscreen isoluminance to determine isoluminance, but state that the values "were checked by flicker photometry" (p. 150), although no further details are provided. Kempner, Aggarwala, Zemon, Gordon, Hainline, and Riddell (1996) used visually evoked potentials to assess isoluminance of checkered matrices.

3. Accurate assessment of isoluminance using HFP can also inspire more precise use of other manipulations of luminance contrast. For example, although dynamic random luminance masking (see, e.g., Barbur, Harlow, \& Plant, 1994; Birch, Barbur, \& Harlow, 1992) may disrupt attentional processes in word recognition, its use for other types of stimuli may benefit from establishing more precisely the perceived luminance of the individual elements within each scintillating masking display (see, e.g., Heywood, Cowey, \& Newcombe, 1994).

(Manuscript received March 31, 2006; revision accepted for publication May 17, 2006.) 